\title{
Effect of Temperature and Micro structural Evolution of Magnesium and Aluminium Alloy using Vacuum Diffusion Bonding
}

\author{
R. J. Golden Renjith Nirmal, Hariharan R, R Shravanan
}

\begin{abstract}
This work is directed to acquire better understanding and portrayal of the dissemination holding of comparable and disparate metals. It additionally meant to get ideal parameters for dispersion holding of aluminum covering over magnesium compound with Aluminum composite. This work targets building up a basic strategy to get dispersion holding joints at moderately not ease. On one hand, the exploration is expected to set up a strategy. This technique is concocted to contemplate the physical wonders that have huge effect on dissemination holding, for example, time, temperature, weight on joints and metallurgical qualities. Elastic and shear tests are to be directed. This work is directed to acquire better understanding and portrayal of the dispersion holding of comparable and unique metals. It likewise intended to ge $t$ ideal parameters for dissemination holding of aluminum covering over magnesium combination with aluminum composite. These two metals are jointed inside the kick the bucket in the wake of completing surface treatment. At that point the bite the dust is kept inside the dispersion holding machine by shifting the time, temperature, weight by methods for burden.
\end{abstract}

Keyword : Aluminium composite, Mettalurgical qualities, Shear tests

\section{INTRODUCTION}

AZ80 and AA 7075 finds larger relevance altogether horizons of commercial sectors attributable to their distinctive options viz., tenuity, high specific strength and smart plasticity. they're thought of as subtle materials utilized usually with the target of minimizing the structural weight, increasing fuel potency and to scale back to induced stress at higher accelerations[19],[21],[22]. Weld ability of those alloys could be a vital task and poses challenges as a result of the formation of oxides and intermetallics within the bond region. The refractory chemical compound film of $\mathrm{Mg}$ \&amp; $\mathrm{Al}$ forms inclusions within the heat-affected zone. Moreover, $\mathrm{Mg}$ exhibits thermal crispness creating the attachment of $\mathrm{Mg} / \mathrm{Al}$ dissimilar material troublesome by the traditional fusion attachment techniques. Mechanical and metallographic examinations reveal the formation of distortions and crack within the heat affected zone of $\mathrm{Mg}$. However, diffusion bonding is found to be appropriate for connexion these alloys while not abundant issue. The vacuum diffusion bonding with

Revised Manuscript Received on August 22, 2019.

R. J. Golden Renjith Nirmal, Department of Mechanical Engineering, Bharath Institute of Higher Education and Research, Chennai, Tamilnadu, India. Email: goldenrenjith@gmail.com

Hariharan R, Department of Mechanical Engineering, Bharath Institute of Higher Education and Research, Chennai, Tamilnadu, India. Email: mech.hariharan17@gmail.com

R Shravanan, Department of Mechanical Engineering, Bharath Institute of Higher Education and Research, Chennai, Tamilnadu, India. Email: sharmtech@gmail.com the event of advanced pc and vacuum techniques is employed in connexion brittle and dissimilar materials. after, the cracks, distortion and segregation created throughout fusion attachment is also eliminated in vacuum diffusion bonding[14],[16],[18].

\begin{tabular}{|l|c|c|}
\hline Mechanical Properties & Mg alloy & Al alloy \\
\hline Density $\left(\mathbf{K g} / \mathbf{m}^{3}\right)$ & $1.78 \times 10^{3}$ & $2.9 \times 10^{3}$ \\
\hline $\begin{array}{l}\text { Ultimate Tensile } \\
\text { strength (MPa) }\end{array}$ & 351 & 580 \\
\hline Elongation (\%) & 17 & 11 \\
\hline Shear strength (MPa) & 199 & 342 \\
\hline
\end{tabular}

Table 1: Mechanical properties of the base metal

\section{EXPERIMENTAL ANALYSIS}

Rectangular framed examples (45 millimeter x 45 millimeter) were machined from moved plates of ten mm thickness metallic component (AZ80) and metal (AA7075) composites. The cleaned and with synthetic compounds treated examples were stacked in a very bite the dust made of $316 \mathrm{~L}$ hardened steel and furthermore the whole dissemination holding arrangement, appeared in Fig. 2, was embedded into a chamber (vacuum weight of a hundred and forty weight unit is kept up) [13],[15],[17]. The examples region unit het up to the holding temperature exploitation acceptance chamber with a warming pace of $250 \mathrm{C} / \mathrm{min}$; parallel the predefined weight was applied. when the finish of holding, the examples region unit cooled to temperature before expulsion from the chamber. twenty seven preliminaries of disparate joints region unit imaginary exploitation totally various combos of holding temperature, holding weight and holding time.

\section{A. Effect of Pressure}

\begin{tabular}{|c|c|c|c|c|}
\hline Sl. No & Temperature & Pressure & Time & Remarks \\
\hline 1. & 350 & 10 & 15 & Not Bonded \\
\hline 2. & 375 & 10 & 15 & Bonded \\
\hline 3. & 400 & 10 & 15 & Bonded \\
\hline 4. & 425 & 10 & 15 & Bonded \\
\hline 5. & 450 & 10 & 15 & Deformed \\
\hline
\end{tabular}

Table 3: Bonded samples 


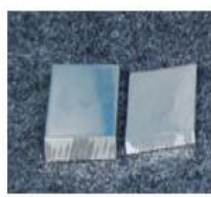

(a) Not Bonded Specimen

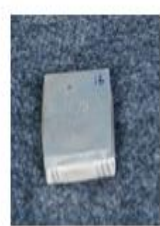

(b) Bonded Specimen

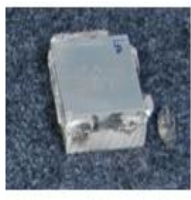

(c) Deformed Specimen

\section{RESULTS AND DISCUSSION}

The interface of AZ80 Mg combination/AA7075 Al composite dispersion justified joint made the plain dissemination between the Az80 Mg compound substrate and consequently the AA7075 Al amalgam substrate inside the state of the dissemination holding. After the holding strategy, the large scale twisting isn't determined at the justified examples[8],[10],[12]. All justified examples were made with sound holding with none little pores, smaller scale split and compound. The new brilliant segment is made at the interface. with regards to $\mathrm{Mg}-\mathrm{Al}$ segment graph, the new segment of $\mathrm{Mg}-\mathrm{Al}$ intemetallics is made once the warming temperature is $375 \mathrm{oC}$ to $425 \mathrm{oC}$. There is a clear limit between the AA7075 $\mathrm{Al}$ composite substrate and hence the dispersion zone. Be that as it may, the limit isn't evident between the Az80 Mg compound substrate and along these lines the dissemination zone. The testing examples are described by methods for optical magnifying instrument and furthermore examining electron magnifying lens (SEM).

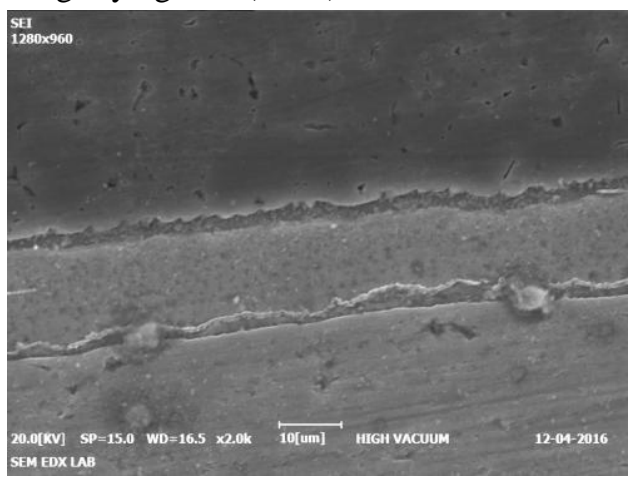

Figure - 1SEM image for the test specimen

\section{CONCLUSION}

The streamlining of holding parameters for dispersion holding magnesium AZ80 combination and aluminum AA7075 amalgam are to be diffused in a dissemination holding machine and the kick the bucket is kept inside the dispersion holding machine by differing the time, temperature, weight by methods for burden. Before making dispersion holding gear, tests are led with high costly and basic installation which is kept inside an enlistment heater in cinching position to get dissemination reinforced joints. Hot press dissemination holding hardware is manufactured and checked with analyses so it is fit for rendering exact dispersion holding joints with offices to quantify parameters and to explore the overly plastic dissemination holding joints. This technique is formulated to ponder the physical marvels that have noteworthy impact on dispersion holding, for example, time, temperature, weight on joints and metallurgical attributes. Tractable and shear tests are to be directed and optical Microscope and smaller scale hardness test are additionally led[1],[3],[5]. For the dispersion holding of Az80 Magnesium composite and AA7075 Aluminum compound, the most extreme shear quality was acquired for the example reinforced at $400 \mathrm{oC}, 10 \mathrm{MPa}$ and 15 minutes. The tractable shear quality of the reinforced examples was observed to be expanded with expanding temperature until a most extreme worth is come to past which it diminished.

\section{REFERENCES}

1. Tatikonda, N.C. \& Naveenchandran, P. 2019, "The behaviour of a compression ignition engine under the influence of diesel and microalgae biodiesel blends", International Journal of Mechanical and Production Engineering Research and Development, vol. 9, no. 4, pp. 447-456.

2. Tatikonda, N.C. \& Naveenchandran, P. 2019, "An experimental assessment on the impact of injection pressure on the characteristics of a diesel engine powered with the blend of diesel and microalgae biodiesel", International Journal of Engineering and Advanced Technology, vol. 8, no. 6, pp. 3284-3291.

3. Karthikeyan, S., Raman Balasubramanian, S.R., Ramesh, B., Raghul, S. \& Sathish Kumar, S. 2019, "The automatic solar tracker chronicles", International Journal of Recent Technology and Engineering, vol. 8, no. 1, pp. 312-315.

4. Hema, R., Sundararajan, M. \& Balaji, S. 2019, "Smartphone control robot with automatic firing gun", International Journal of Innovative Technology and Exploring Engineering, vol. 8, no. 9 Special Issue 3, pp. 625-627.

5. Saritha, B., Chockalingam, M.P. \& Aswathy, M. 2019, "Degradation of anionic dye using Fe/Tio2 composite by photocatalysis", International Journal of Innovative Technology and Exploring Engineering, vol. 8, no. 9 Special Issue 3, pp. 788-791.

6. Saritha, B., Maria Subashini, L. \& Aswathy, M. 2019, "Utilization of spent coffee grounds for compost production", International Journal of Innovative Technology and Exploring Engineering, vol. 8, no. 9 Special Issue 3, pp. 908-910.

7. Fernando, J.K., Meikandaan, T.P. \& Hemapriya, M. 2019, "Better utilisation of bottom ash in coal fired thermal power station", International Journal of Innovative Technology and Exploring Engineering, vol. 8, no. 9 Special Issue 3, pp. 898-900.

8. Kumar, K.S., Kiruthiga, K. \& Thendral, S. 2019, "Experimental analysis on fractional substitution of bond by utilizing rice husk cinder", International Journal of Innovative Technology and Exploring Engineering, vol. 8, no. 9 Special Issue 3, pp. 1163-1165.

9. Vignesh, P., Madan, P., Mohankumar, D. \& Naveenchandran, P. 2019, "Optimization of four stroke c.i. engine performance by using statistical techniques (mathematical method)", International Journal of Recent Technology and Engineering, vol. 8, no. 2, pp. 1685-1691.

10. Bharanidharan, S., Sathiyamurthy, K. \& Sheeba, B. 2019, "Using co-precipitation method determining synthesis and characterization of fe doped zinc oxide nanoparticles", International Journal of Innovative Technology and Exploring Engineering, vol. 8, no. 9 Special Issue 3, pp. 705-707.

11. Jeevanandan, D. \& Vino, J.A. 2019, "Heat recovery from boiler blowdown water by using heat exchanger in thermal power plant", International Journal of Mechanical and Production Engineering Research and Development, vol. 9, no. 3, pp. 219-222.

12. Rakesh, N.L., Balambica, V. \& Kannan, S. 2019, "Biogas extraction from waste orange peel by digestion process", International Journal of Mechanical and Production Engineering Research and Development, vol. 9, no. 3, pp. 323-330.

13. Meenakshi, C.M. \& Krishnamoorthy, A. 2019, "The mechanical characterization of mono and hybrid fiber reinforced composites using experimental and finite element analysis methods", International Journal of Mechanical and Production Engineering Research and Development, vol. 9, no. 3, pp. 189-196. 
14. Mohankumar, D., Prem Jayakumar, M., Sabarsish, R. \& Naveen Chandran, P. 2019, "Modeling and experimental investigation on centrifugal blower by computational fluid dynamics", International Journal of Mechanical and Production Engineering Research and Development, vol. 9, no. 3, pp. 331-340.

15. Balambica, V., Deepak, V. \& Kumar, S. 2019, "Design and efficiency of an asymmetric gear", International Journal of Mechanical and Production Engineering Research and Development, vol. 9, no. 3, pp. 223-230.

16. Manavalan, S., Balakrishnan, G. \& Ramasubramaniam, S. 2019, "An effect of cobalt oxide nano additive with biodiesel blends using cidi diesel engine", International Journal of Mechanical and Production Engineering Research and Development, vol. 9, no. 3, pp. 211-218.

17. Golden Renjith Nimal, R.J., Sivakumar, M. \& Esakkimuthu, G. 2019 , "An investigation on mechanical properties and microstructure of $\mathrm{mg} / \mathrm{al}$ alloys using zn interlayer during diffusion bonding", International Journal of Mechanical and Production Engineering Research and Development, vol. 9, no. 3, pp. 125-130.

18. Hariharan, R., Raja, R. \& Vasu, S. 2019, "Mechanical and tribological behaviour of thin tan coating produced on AISI 1018 substrate by DC magnetron sputtering", International Journal of Recent Technology and Engineering, vol. 7, no. 6, pp. 591-598

19. Manavalan, S., Rai, R., Kumar, R.R., Chaudhary, R.K. \& Chaudhary, S.K. 2019, "Impact of modified piston - A review", International Journal of Recent Technology and Engineering, vol. 8, no. 6, pp. 616-620.

20. Manavalan, S., Gopi, A., Arivarasu, J., Abishek Ahi, A. \& Chandru, S. 2019, "Review on ceramic disc brake system", International Journal of Recent Technology and Engineering, vol. 7, no. 6, pp. 612-615.

21. Sabarish, R. \& Jeya Kumar, M.P. 2019, "The design and analysis of piston - Steady state thermal analysis using "ansys"", International Journal of Mechanical and Production Engineering Research and Development, vol. 9, no. 3, pp. 197-204.

22. Ravi, D. 2019, "CFD simulation of solar loading in car", International Journal of Mechanical and Production Engineering Research and Development, vol. 9, no. 3, pp. 231-236.

\section{AUTHORS PROFILE}

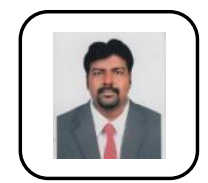

R. J. Golden Renjith Nirmal Assistant Professor, Department of Mechanical Engineering, Bharath Institute of Higher Education and Research, Chennai, India.

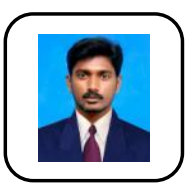

Hariharan R Assistant Professor, Department of Mechanical Engineering, Bharath Institute of Higher Education and Research, Chennai, India.

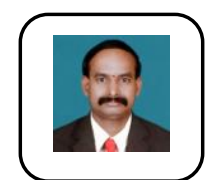

R Shravanan Assistant Professor, Department of Mechanical Engineering, Bharath Institute of Higher Education and Research, Chennai, India. 